\title{
Development of a gas fired Vuilleumier heat pump for residential heating
}

\section{Carlsen, Henrik}

Published in:

Proceedings of the 24th Intersociety Energy Conversion Engineering Conference

Link to article, DOI:

10.1109/IECEC.1989.74788

Publication date:

1989

Document Version

Publisher's PDF, also known as Version of record

Link back to DTU Orbit

Citation (APA):

Carlsen, H. (1989). Development of a gas fired Vuilleumier heat pump for residential heating. In Proceedings of the 24th Intersociety Energy Conversion Engineering Conference (Vol. Volume 5, pp. 2257-2263). IEEE. https://doi.org/10.1109/IECEC.1989.74788

\section{General rights}

Copyright and moral rights for the publications made accessible in the public portal are retained by the authors and/or other copyright owners and it is a condition of accessing publications that users recognise and abide by the legal requirements associated with these rights.

- Users may download and print one copy of any publication from the public portal for the purpose of private study or research.

- You may not further distribute the material or use it for any profit-making activity or commercial gain

- You may freely distribute the URL identifying the publication in the public portal

If you believe that this document breaches copyright please contact us providing details, and we will remove access to the work immediately and investigate your claim. 


\title{
DEVELOPMENT OF A GAS FIRED VUILLEUMIER HEAT PUMP
} FOR RESIDENTIAL HEATING

\author{
H. Carisen \\ Laboratory for Energetics \\ The Technical University of Denmark \\ DK-2800 Lyngby
}

\begin{abstract}
A natural gas driven heat pump based on the Vuilleumier principle has been developed for use in single family houses. The result of the development was a heat pump with a heat output of $7.5 \mathrm{~kW}$ at a COP of 1.62 based on the lower heat content of the gas fuel. In this operating condition the heater temperature was $700 \mathrm{C}$, the temperature to the heating system was $55 \mathrm{C}$ and the temperature in the cold source was $5 \mathrm{C}$.

The heat pump uses helium as working fluid at $20 \mathrm{MPa}$ mean pressure, and it is designed as a semihermetic unit. A new crank mechanism was developed, that was distinguished by very small loads on the piston rings.

The advantages and disadvantages of the Vuilleumier principle for heat driven heat pumps are also described. Results from the extensive experimental work are presented. Finally a short description of a new $20 \mathrm{~kW}$ Vuilleumier heat pump is presented.
\end{abstract}

\section{INTRODUCTION}

Since 1979 research and development have been carried out on a heat driven heat pump based on the Vuilleumier principle. The heat pump was designed for use in single family houses, and it is driven by natural gas.

The project has been financed mainly by the Danish Ministry of Energy, and the work has been carried out by The Laboratory for Energetics at The Technical University of Denmark, and by AC Energi.

The paper describes the design of the heat pump and the advantages and disadvantages of the Vuilleumier principle for heat driven heat pumps. Results from the extensive experimental work are presented. Finally a short description of a new $20 \mathrm{~kW}$ Vuilleumier heat pump is presented.

\section{THE VUILLEUMIER MACHINE}

Like the stirling cycle the Vuilleumier is a closed cycle, where the working gas is kept inside the cylinders, and heat is added to and removed from the cycle trough heat exchangers. Fig. 2.1 shows a schematic Vuilleumier heat pump. It consists of a hot and a cold cylinder, with a displacer piston in each cylinder. The cylinders are connected with a channel.

The cylinder volumes over and under the displacer are connected through two heat exchangers separated by a regenerator. The regenerator works as a heat store when the working gas flows between the hot and the cold cylinder volume.
In the Vuilleumier heat pump, heat enters the cycle at a high temperature $\mathrm{T}_{\mathrm{H}}$ in the hot expansion volume by means of a burner. Heat enters the cycle at a low temperature $\mathrm{T}_{\mathrm{C}}$ in the cold expansion volume. Heat is delivered to the radiator system from the intermediate compression volumes at a medium temperature $\mathbf{T}_{\mathrm{I}}$.

From fig. 2.1 it can be seen that the piston rod in the cold cylinder acts as a small power piston as in a stirling engine. The produced power is approximately proportional to the area of the rod. By proper dimensioning of the piston rod diameter in the cold cylinder it is possible to produce adequate power at the desired rotational speed to compensate for the power losses due to frictional pressure drop through the heat exchangers and regenerators and the power losses caused by mechanical friction. An electric motor is therefore only necessary for starting.

In order to maximize heat transport and minimize pressure losses in the heat exchangers the working gas is normally hydrogen or helium. The working gas mean pressure is usually between $5 \mathrm{MPa}$ and $20 \mathrm{MPa}$.

\subsection{Disadvantages for the Vuilleumier cycle}

The displacers move the working gas between the 4 cylinder volumes over and under the two displacers as shown in fig. 2.2. From 1) to 2) the displacer in the hot cylinder is moved so that the working gas flows from the volume with the temperature $T_{I}$

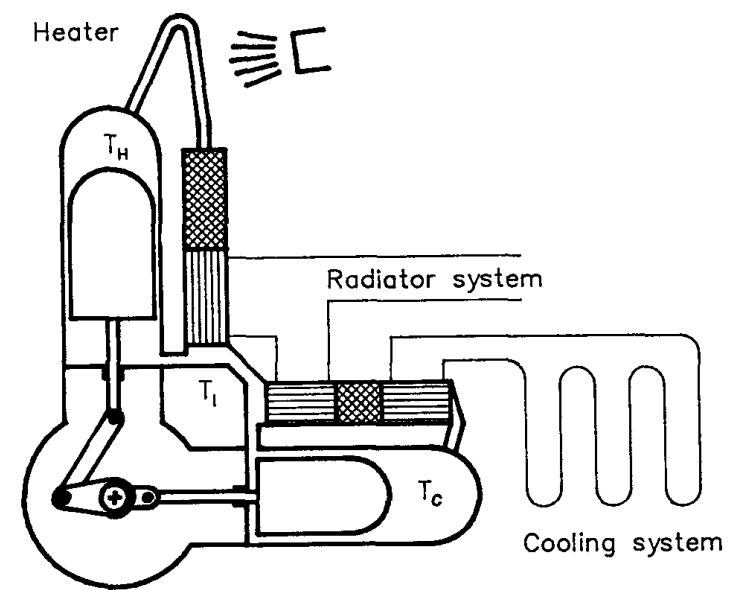

Fig. 2.1. Schematic Vuilleumier heat pump. 

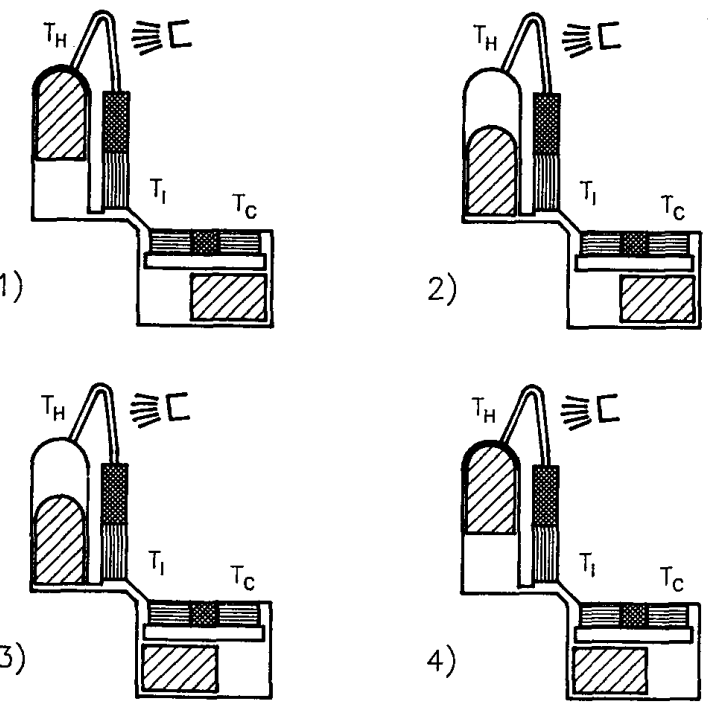

Fig. 2.2. The Vuilleumier cycle.

(at f.ex. $55 \mathrm{C}$ ) to the hot volume with the temperature $\mathrm{T}_{\mathrm{H}}$ (at f.ex. $700 \mathrm{C}$ ). The pressure in all cylinder volumes will then increase. From 3) to 4) the displacer in the hot cylinder is moved back and the pressure will then decrease. If the cylinder volumes were isothermal, heat would have to be removed from the volume to the left in the cold cylinder in order to maintain the temperature $T_{I}$ when the pressure is increasing. In the same way heat has to be removed from the volume to the right in the cold cylinder in order to maintain the temperature $\mathrm{T}_{\mathrm{C}}$ (at f.ex. $5 \mathrm{C}$ ) when the pressure is decreasing.

From 2) to 3) heat is supplied to the hot cylinder volume, and from 4) to 1) heat is removed from the cylinder volume with intermediate temperature. If these volumes also are assumed isothermal and the heat exchangers and regenerators are assumed perfect the cycle has a COP identical to the Carnot cycle.

Unfortunately the cylinder volumes are not isothermal but nearly adiabatic. That means that the temperature in the volume in the cold cylinder increases from 1) to 2) and decreases from 3) to 4). When the displacer in the cold cylinder is moved from 2) to 3) the heated gas flows through the heat exchanger with the temperature $T_{I}$, and the heat is supplied to the heat exchanger brine. From 4) to 1) the cooled gas flows through the heat exchanger with the temperature $\mathrm{T}_{\mathrm{C}}$, and heat is removed from the brine in the heat exchanger. Even if the heat exchangers and the regenerator are perfect, the COP will be lower than for the Carnot cycle because the mean temperature in the cylinder volumes differs from the temperature in the heat exchanger brine. As the changes of temperature in the cylinder volumes are proportional with the changes of pressure, the indicated COP will decrease with increasing change of pressure over the cycle

This is of course the same for the stirling cycle, but when the temperature difference between the two cylinder volumes is small compared with the change of temperature in the cylinder volumes as in an engine, the reduction of the efficiency is not so significant. For a cooling cycle based on the stirling or the
Vuilleumier cycle the temperature difference between the two cylinder volumes is often smaller than the change of temperature in the cylinder volumes themselves, and the COP for the cooling cycle is seriously reduced.

Another disadvantage of the Vuilleumier cycle is, that the specific output is low. For a desired heat output the machine must be large, and therefore rather expensive. That is because of the missing volumetric compression in the cycle, which reduces the maximum possible pressure variation. It does, however, improve the indicated $\mathrm{COP}$ as explained above.

\subsection{Advantages for the Vuilleumier cycle}

The Vuilleumier cycle has several obvious advantages:

- Simple closed cycle with few moving parts, which makes it possible to design the Vuilleumier heat pump as a semihermetic unit, if the starter motor is incorporated in a pressurised crank case.

- External heat supply to the closed cycle from a burner, from which it is easier to control the pollution compared to a gas or diesel engine driven heat pumps.

- potential for high COP despite the disadvantages of the stirling/Vuilleumier cycle as a cooling cycle. The few moving parts and the low mechanical friction makes the obtainable COP very competitive for smaller heat driven heat pumps compared to the absorbtion type and the gas or diesel engine driven heat pump.

- low noise because of the nearly sinusoidal pressure variation and the continuous heat supply. If the cylinders are arranged in a $\mathrm{V}$ as shown in fig. 2.1 the vibrations can also be reduced to a minimum.

- low mechanical forces on the moving parts, which makes it possible to use life time crease lubricated needle and ball bearings and to attain life times at more than 30.000 hours.

\section{HEAT PUMP VP1 WITH A HEAT OUTPUT AT 7.5 KW}

For the heating of a typical Scandinavian single family house is a heat pump with a heat output of $7.5 \mathrm{~kW}$ developed. Table 3.1 shows the specifications for the heat pump VP1, and in fig. 3.1 a draft of the heat pump is shown. The two cylinders are arranged in a $\mathrm{V}$ in order to minimize vibrations. The heat pump is hanging with the heater and burner section downward as shown in fig. 3.2 .

A special crank mechanism described below moves the displacer pistons with a phase angle at approximately $90^{\circ}$. Helium is used as working gas at a $20 \mathrm{MPa}$ mean pressure.

\subsection{Crank mechanism}

The large forces on the working piston in a stirling engine demand a conventional oil lubricated crank system. A seal for the separation of the working gas in the cylinder volumes and the oil in the crank case has turn out to be very difficult to manufacture.

In the Vuilleumier machine the pressure difference between the volumes over and under the displacer piston is caused by the flow resistance in the heat exchangers and the regenerator, and the mechanical forces are therefore small. That makes the use of 
Tab. 3.1. Specifications for $7.5 \mathrm{~kW}$ gas driven heat pump. COP is based on the lower heat content of the gas.

Bore, mm

Stroke, mm

Max mean pressure, $\mathrm{MPa}$

Working gas

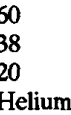

Max. heat output, $\mathrm{kW}$

COP

1.62

at: Heater temp., C

Temp., heating system, $\mathrm{C}$

Temp., cooling system, C

700

55

RPM at max. output

Dimensions and weight (inc. frame):

Height, m

Width, m

Depth, m

Weight, $\mathrm{kg}$

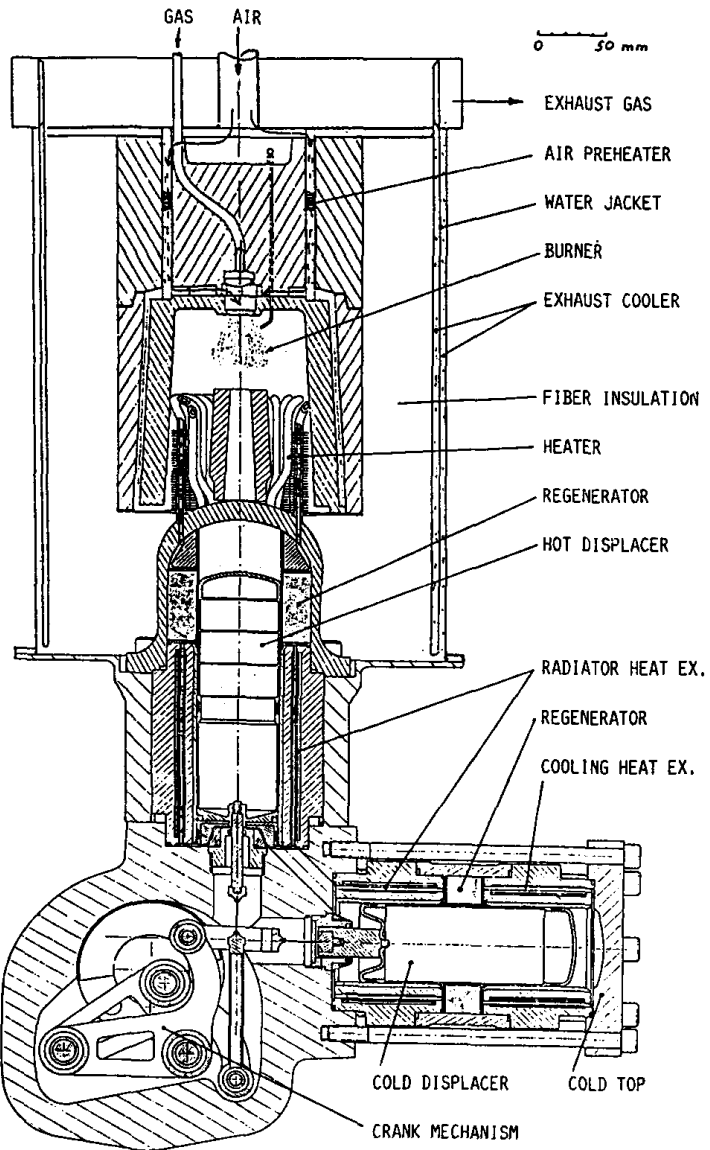

life time, grease lubricated needle and ball bearings possible. In this way oil in the crank case is avoided.

In order to reduce the demands on the piston rod seal between the working gas volumes and the crank case the heat pump is made as a semihermetic unit, where there is mean pressure in the crank case. The starter motor is incorporated in the pressurized crank case so that all seals to the atmosphere are static $\mathrm{O}$-ring seals.

As common practice for stirling engine design PTFE-based seals are used for the displacer pistons and the piston rods. In order to reduce the wear and the mechanical losses the guide forces on the displacer pistons are eliminated by means of a special developed crank mechanism derived from the principles known from Andy Ross' machines. At the same time, this crank mechanism makes it possible to place the hot and the cold cylinder close to each other, so that the channel between the cylinders can be very short.

The crank mechanism consists as shown in fig. 3.3 of two triangular connecting members, $\mathrm{ADX}$ and $\mathrm{ASY}$. The distances $\mathrm{AD}$, $\mathrm{DX}, \mathrm{AS}$ and $\mathrm{SY}$ are all the same and $\mathrm{AD}$ is perpendicular to $\mathrm{DX}$ as AS is perpendicular to SY.

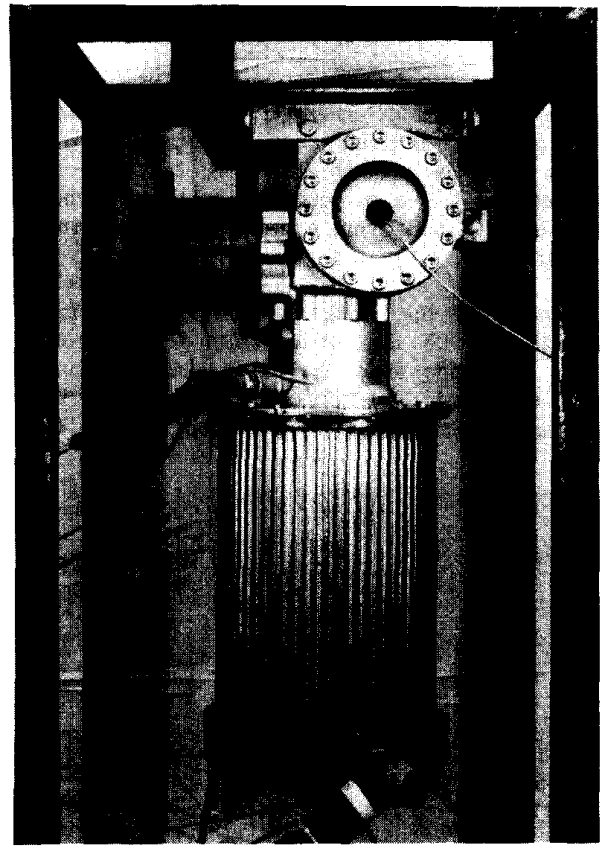

Fig. 3.2. The gas driven heat pump VP1 hanging with the heater and burner section downward.

Fig. 3.1. Draft of the $7.5 \mathrm{~kW}$ gas driven Vuilleumier heat pump. 


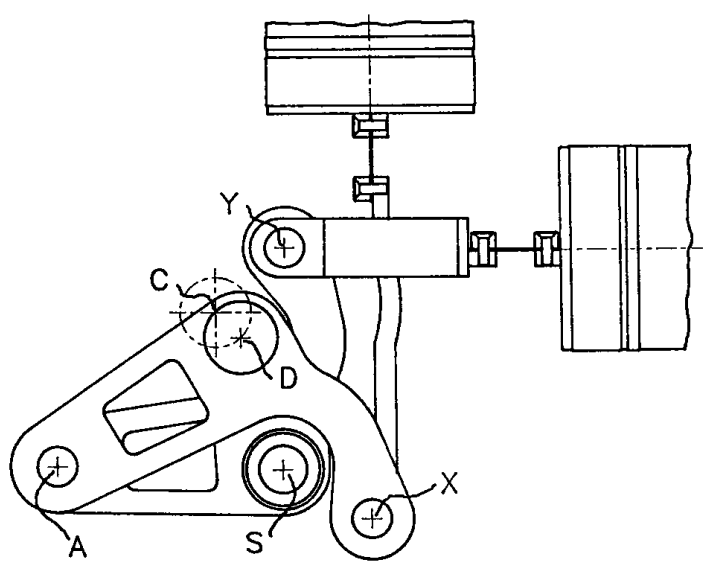

Fig. 3.3. Crank mechanism developed for the heat pump.

The member ADX is connected to a crank in the pivot $D$, which rotates around the axis $\mathrm{C}$. The two members are connected in the pivot A. The member ASY rotates around the pivot $S$, which is fixed in the crank case. The shape of the members is the same.

The two displacer pistons are connected in the pivots $\mathrm{X}$ and $\mathrm{Y}$. When point $D$ rotates around $C$, the pivots $A$ and $X$ moves up and down with a phase angle of approximately $90^{\circ}$. As the member ASY is rotating around $S$, the pivot $Y$ follows the movement of $\mathrm{A}$, but perpendicular to the movement of $\mathrm{X}$. The movement of $\mathrm{X}$ and $\mathrm{Y}$ has a stroke which is approximately $\sqrt{2}$ the diameter of $\mathrm{D}$.

The design of the crank mechanism results in a movement perpendicular with the stroke, which is less than $10 \%$ of the stroke. The guide forces on the displacer pistons are therefore nearly eliminated. The connection between the displacer piston and the connecting rods is made from a piece of leaf spring.

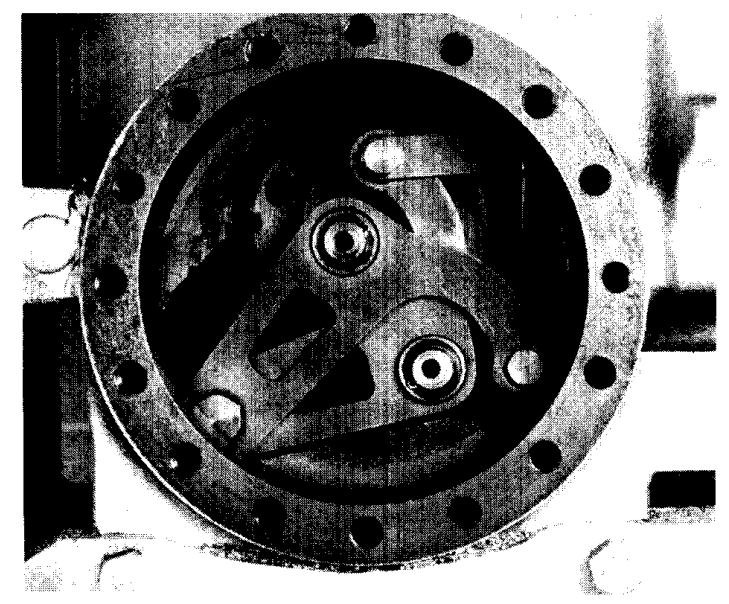

Fig. 3.4. Crank mechanism mounted in the crank case of VP1.
The crank mechanism was tested for more than 4000 hours in a test stand, where piston ring wear was measured each week, and a prototype of the heat pump has been running for approximately 3.500 hours. There were no problems during the tests with the piston rings and the bearings, and results from the tests seems in agreement with the calculated life time of 30.000 hours.

Fig. 3.4 shows the opened crank case for the heat pump VP1. The crank mechanism is patented in USA, Japan and several european countries.

\subsection{Heat exchangers}

In order to reduce the length of the connections between the cylinder volumes and the heat exchangers, an annular design of the heat exchangers and regenerators is used (see fig. 3.5). The two heat exchangers in the cold cylinder and the heat exchanger connected to the compression space in the hot cylinder are made from thin stainless tubes, where the working gas is flowing inside the tubes, while the brine is flowing outside in an annular chamber between an inner and outer mantle. The inner mantle is also used as the cylinder bore for the displacer pistons.

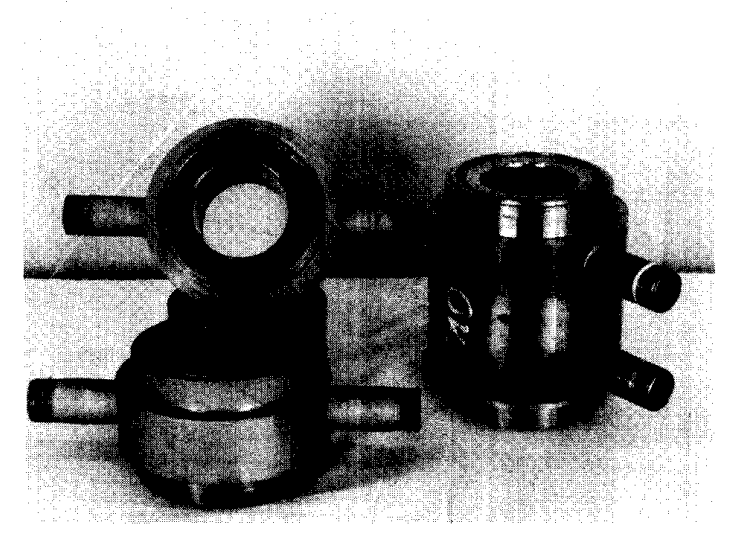

Fig. 3.5. The long heat exchanger for the hot cylinder and the two heat exchangers for the cold cylinder.

\subsection{Heater}

Because of the large internal pressure and the high temperatures the demands on the heater top are extreme. Furthermore the large temperature difference causes excessive thermal stresses in the cylinder wall. In order to reduce the stresses as much as possible the top is design as a half sphere. The thermal and mechanical stresses have been calculated by means of the finite element method.

The material for the top is VEW 240 from Vereinigte Edelstahlwerke, Austria (Werkstoff Nr. 1.4962). The composition is shown in tab. 3.2.

As the regenerator had to be shortened, the stresses was increased compared to the calculations, and permanent deformation of the top was observed. A better material or an increased thickness of the cylinder wall is necessary. 
Tab. 3.2. Composition of iron based materials for the heater top and tubes (\%)

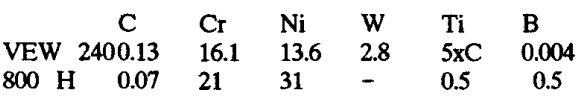

The heater tubes are bent $180^{\circ}$ and connect the expansion volume with the top of the hot regenerator. On the outer side of the tubes there are fins as shown on fig. 3.6. The tubes are made from Incoloy $800 \mathrm{H}$ from Henry Wiggens. The tubes are nickel brazed to the top in a vacuum furnace.

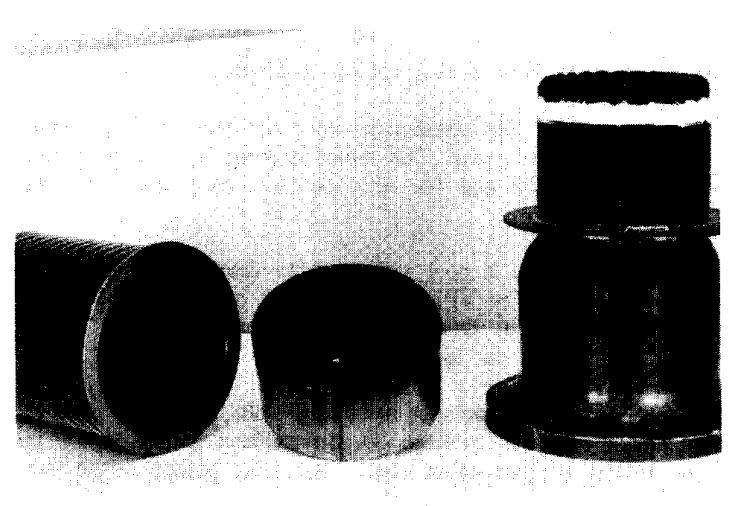

Fig. 3.6. Air preheater, regenerator and heater for the heat pump VP1.

\subsection{Regenerators}

The regenerator matrix is normally made of woven net of thin stainless steel, which is stacked and sintered to give structural stability.

It is however an expensive method. It is expensive to weave the thread and there is some waste when the circular parts are stamped out, especially for an annulus construction. The regenerators are therefore made from thread bought on reels. First the thread is drawn between two gear wheels in mesh in a continuous process, where the thread is made zig-zag shaped Afterwards the thread is pressed in a tool to the desired shape and filler factor.

The advantage of this method is that there are only two loose ends, so that sintering and brazing is not necessary. In addition there is no waste and thread on reels is very cheap compared to woven net.

Measurements on the pressure loss through the regenerator made in this way agrees with measurements on regenerators made from woven net. Fig. 3.6 shows the hot regenerator for the heat pump VP1.

\subsection{Burner system}

The air preheater is also made as an annulus heat exchanger with counterflow. Thin corrugated sheet stainless steel originally meant for heat exchangers for F16 combat fighters has been brazed to a upper and lower part, so that air flows inside and exhaust gases outside in the corrugations (see fig. 3.6). Ceramic fiber felt is used in order to keep the gas flow between the corrugations.

The combustion chamber and the hot parts in the burner are cast from ceramic material normally used for fire bricks. The combustion chamber and the preheater are isolated with ceramic fiber isolation.

In order to reduce the heat loss from the burner system, it is made very compact, and it is surrounded by a water jacket so that the heat conduction through the insulation is directed into the water in the radiator system. The water jacket is in the same time used as a exhaust gas condenser before the exhaust goes into the chimney. The exhaust gas is in this way cooled to a temperature at $1^{\circ}-2^{\circ}$ degrees above the water return temperature.

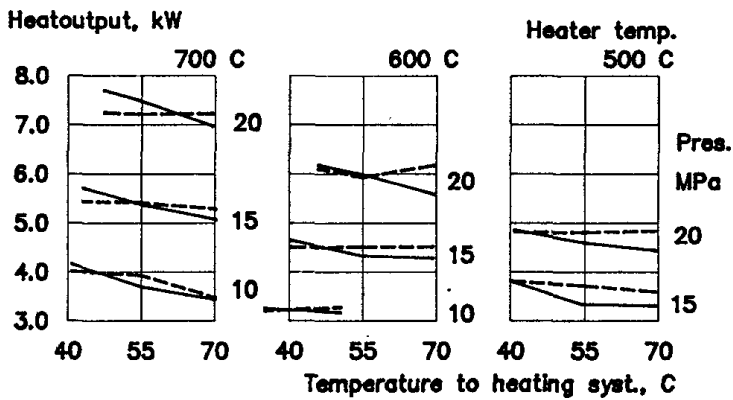

COP, heating
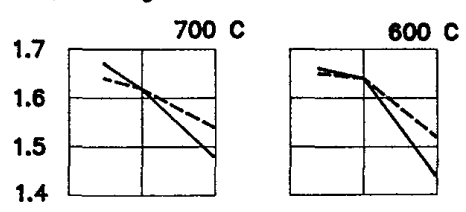

Heoter temp.
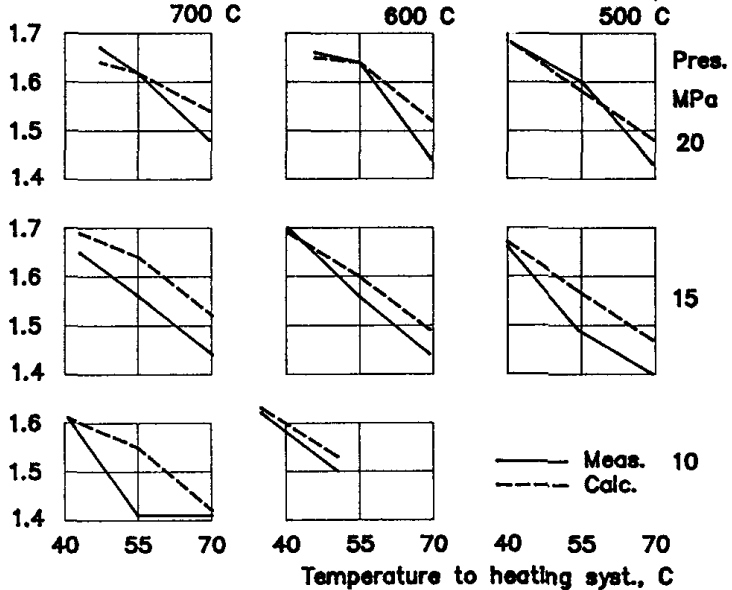

Fig. 3.7. Measured and calculated heat output and COP for a 7.5 $\mathrm{kW}$ gas driven heat pump. The temperature in the coolant returning to the heat pump is $5 \mathrm{C}$. COP is based on the lower heat content of the gas fuel 


\subsection{Specifications and results}

Specifications for the heat pump for residential heating are shown on table 3.1 .

Fig. 3.7 shows measured values for heat output and COP as a function of temperature in the water flow to the heating system. The results are shown for three different temperatures of the heater tubes $(500 \mathrm{C}, 600 \mathrm{C}$ and $700 \mathrm{C})$, and for three different mean pressures (10 $\mathrm{MPa}, 15 \mathrm{MPa}$ and $20 \mathrm{MPa}$ ). The temperature in the cooling brine returning to the machine is $5 \mathrm{C}$ for all tests. The COP is based on the lower heat content of the gas fuel.

The figure also shows a comparison with calculated results from a comprehensive computer program developed for the design of the heat pump [1]. From the figure it can be seen that the computer program predicts the performance for the Vuilleumier heat pump accurately over a wide range of working conditions.

Fig. 3.8 shows the heat output, the COP and the speed as a function of the heater temperature at maximum mean pressure 20 $\mathrm{MPa}$. The temperature to the radiator system is $55 \mathrm{C}$ and the return from the cooling system is $5 \mathrm{C}$. It can be seen that the heat output is reduced with $40 \%$ when the heater temperature is reduced from $700 \mathrm{C}$ to $500 \mathrm{C}$. The COP is only reduced from 1.62 to 1.6 with a maximum of 1.64 at $600 \mathrm{C}$. The large reduction in heat output is due to the decrease in rotational speed when the temperature is reduced. At the same time the pressure losses and heat conduction losses are reduced, and that is the reason why the COP is nearly unchanged. The unexpected performance is also a consequence of the fact that the heat pump has been optimised for power in order to compensate for the low specific output of the Vuilleumier cycle.

As a fast regulation of the output is not necessary for a heat pump, it is possible to regulate the output by means of the temperature in the heater. This is a simple and cheap method compared to a regulation system based on changing the pressure.

Heotoutput, kW

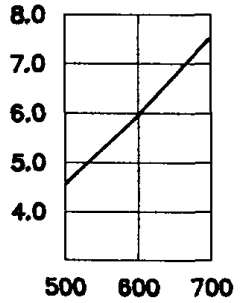

COP
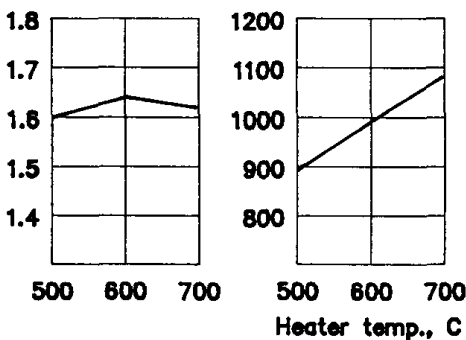

Fig 38. Heat output COP and speed as a function of heater temperature at $20 \mathrm{MPa}$

\section{HEAT PUMP VP2 WITH A HEAT OUTPUT AT $20 \mathrm{KW}$}

In 1985 the development of a Vuilleumier machine, VP2, was initiated, which was approximately 2.5 times the size of the before mentioned heat pump, VP1. This machine was developed as a cooling machine for fishing vessels, as the cooling machine was driven from the heat in the exhaust gases from the main engine. In this way the expenses for the operation of the cooling machine were eliminated. At $350 \mathrm{C}$ heater temperature, $-15 \mathrm{C}$ cooling temperature and $22 \mathrm{C}$ seawater temperature the cooling output was $4 \mathrm{~kW}$ at $1100 \mathrm{rpm}$. Fig. 4.1 shows the cooling machine.

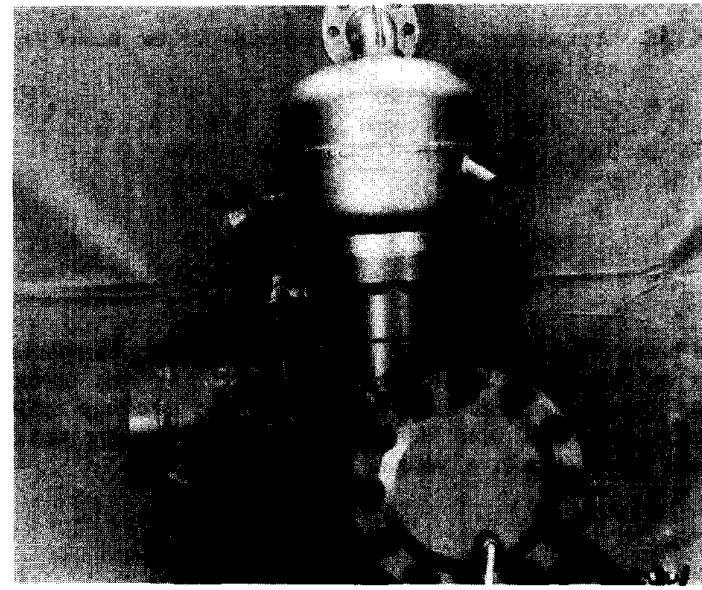

Fig. 4.1. Waste heat driven cooling machine.

The large machine was constructed after the same main principles as the smaller heat pump. The mean pressure was reduced from $20 \mathrm{MPa}$ to $12 \mathrm{MPa}$ and the ratio between bore and stroke was increased.

The cooling machine is now under further development into a gas driven heat pump. The VP2 heat pump will have a heat output at approximately $20 \mathrm{~kW}$. Data for the heat pump and the cooling machine are shown in table 4.1

At the moment four machines are being built. Three machines are going to be used as exhaust gas driven heat pumps on a gas engine driven co-generation plant. The heat pumps utilize the

Tab. 4.1. Specifications for heat pump/cooling machine VP2.

$$
\text { machine }
$$

$$
\text { Heat pump Cooling }
$$

Bore, mm

Stroke, mm

Max. mean pressure, MPa

Working gas

Max. heat output, $\mathrm{kW}$

COP

$\begin{array}{cc}105 & 105 \\ 51 & 51 \\ 12 & 12 \\ \text { Helium } & \text { Helium }\end{array}$

at: Heated temp., C

Temp. to radiator, $\mathrm{C}$

Cooling temp., $\mathrm{C}$

20 heat

1.6

4 cooling

0.35 cooling

Speed

350

55
5

$5-15$

Measures and weight:

Height, m

With, m

Depth, m

Weight, kg
12

0.8

0.5

175
10

0.8

0.5

175 


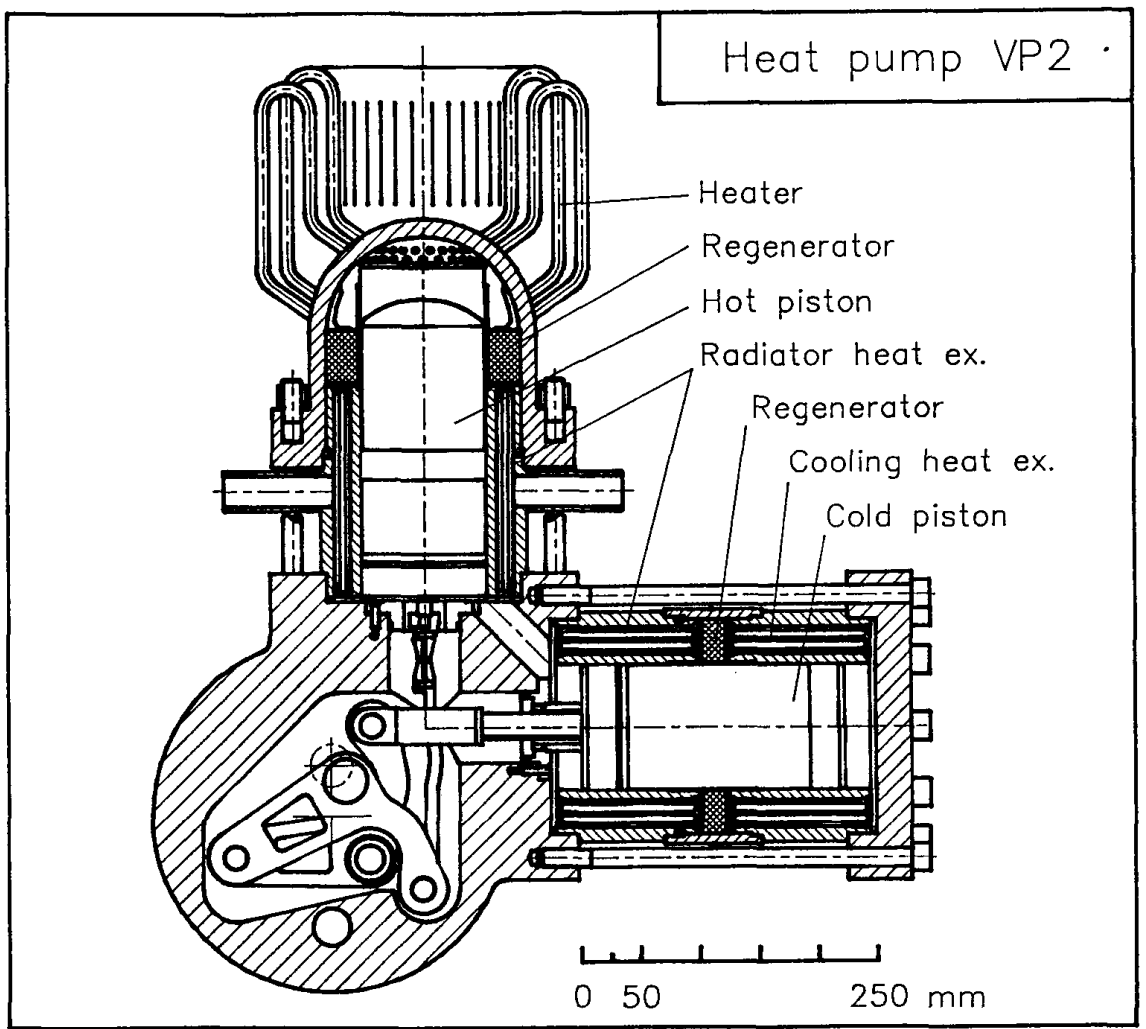

Fig. 4.2. The new $20 \mathrm{~kW}$ heat pump VP2.

heat from the intercooler at $20 \mathrm{C}$ for the heating system at 55 C. The last machine will be equipped with a burner for natural gas. This heat pump will be used for experiments and for field tests. Fig. 4.2 shows a drawing of the VP2 heat pump/cooling machine. The machines should be ready for test in september 1989.

\section{CONCLUSION}

A natural gas driven heat pump based on the Vuilleumier principle has been developed for use in single family houses. The result of the development is a semihermetic unit with the starter motor incorporated in the crankcase. The heat output is $7.5 \mathrm{~kW}$ at a COP of 1.62 based on the lower heat content of the gas fuel. Helium is used as working fluid at $20 \mathrm{MPa}$ mean pressure.

A larger $20 \mathrm{~kW}$ heat pump based on the experience from the 7.5 $\mathrm{kW}$ unit is under development for production in small series mainly for test purpose.

A new crank mechanism was developed for the heat pump and tested for more than 6.000 hours totally, and the results promise more than 30.000 hours lifetime.

The advantage of the Vuilleumier cycle is that it is a single unit which can be made semihermetic, without the need for dynamic seals between the working space and the crank case. The loads on the moving parts and the bearings are approximately $5 \%$ of the loads on a stirling engine with the same geometry and mean pressure. Unfortunately the heat output is only $25 \%$ of a stirling engine driven heat pump, which causes the Vuilleumier heat pump to be large compared to the stirling based heat pump.

When the Vuilleumier or the stirling cycle is used for cooling the COP for the cooling part is less than for a conventional compressor type cooling machine. The low mechanical losses in the Vuilleumier machine compensate partly for that, so that high overall COP can be achieved.

\section{REFERENCES:}

[1] H. Carlsen,"Simulation Model for the Design of Vuilleumier Machines", Paper submittet for ASME Annual Meeting, Dec. 1989. 